\title{
Tratamentos pré-germinativos para sementes de Hymenaea stigonocarpa Mart. ex Hayne
}

\author{
Sérgio Roberto Garcia dos Santos ${ }^{1 *}$ \\ Renata Salaro Stecca e França de Oliveira ${ }^{2}$ \\ Luciana Cantanhede de Souza ${ }^{3}$ \\ Sebastiana Dutra Souza Revoredo da Silva ${ }^{1}$ \\ ${ }^{1}$ Instituto Florestal, Rua do Horto, 931, CEP 02377-000, São Paulo - SP, Brasil \\ ${ }^{2}$ Centro Universitário São Camilo, São Paulo - SP, Brasil \\ ${ }^{3}$ Associação Educacional Nove de Julho, São Paulo - SP, Brasil \\ * Autor para correspondência \\ sergiorgsantos@yahoo.com.br
}

Submetido em 04/03/2016

Aceito para publicação em 09/11/2016

\section{Resumo}

Hymenaea stigonocarpa, conhecida como jatobá-do-cerrado, pertence à família Fabaceae (Leguminosae) e está incluída na categoria de espécie "quase ameaçada de extinção". Seus indivíduos ocorrem em áreas de cerrado e cerradão e suas sementes apresentam dormência física. Em razão dessa característica, este estudo teve por objetivo avaliar diferentes tratamentos pré-germinativos em sementes de $H$. stigonocarpa, sendo eles: imersão em fogo, ácido sulfúrico, ácido clorídrico, acetona, éter e água quente $\left(100^{\circ} \mathrm{C}\right)$, além de escarificação mecânica com lixa e corte do tegumento com alicate de unha e lavagem em água corrente por $2 \mathrm{~h}$. Os resultados obtidos pelos tratamentos foram comparados aos da testemunha, que não foi submetida a nenhum deles. Os parâmetros analisados foram: a porcentagem de germinação, o Índice de Velocidade de Germinação (IVG) e os percentuais de sementes duras e firmes e de sementes mortas. Os resultados finais foram: a) germinação: a água fervente e o ácido sulfúrico foram superiores aos da testemunha; b) IVG: a água fervente, o ácido sulfúrico, o fogo e a lixa foram superiores aos da testemunha; e c) não foram observadas diferenças estatísticas entre a testemunha e os demais tratamentos para o percentual de sementes mortas. Em vista disso, os tratamentos com a água fervente e o ácido sulfúrico se mostraram os melhores, considerando-se os parâmetros analisados.

Palavras-chave: Cerrado; Dormência; Espécie florestal; Espécie quase ameaçada; Espécie nativa

\section{Abstract}

Pre-germination treatments for Hymenaea stigonocarpa Mart. ex Hayne seeds. Hymenaea stigonocarpa, known as Jatoba-do-cerrado, belongs to the family Fabaceae (Leguminosae) and is included in the category "near threatened with extinction." It occurs in cerrado and cerradão areas, and its seeds have physical dormancy. Because of this characteristic, the aim of this study was to evaluate different pre-germination treatments and control in H. stigonocarpa seeds, namely: immersion in fire, sulfuric acid, hydrochloric acid, acetone, ether and hot water $\left(100^{\circ} \mathrm{C}\right)$, and mechanical scarification of the seed coat by roughing with sandpaper or cutting with nail clippers and washing in running water for 2 hours. The parameters analyzed were percentage of germination, 
germination speed index (GSI) and the percentage of hard and firm seeds and dead seeds. The final results were: a) germination: boiling water and sulfuric acid were superior to the control; b) GSI: boiling water, sulfuric acid, fire and sandpaper were superior to the control and c) percentage of dead seeds was not statistically different between the different treatments and control. In conclusion, boiling water and sulfuric acid, were the best treatments, with regard to the parameters examined.

Key words: Cerrado; Forest species; Native species; Numbness; Species near threatened

\section{Introdução}

A espécie Hymenaea stigonocarpa apresenta sinonímia botânica (Hymenaea chapadensis Barb. Rodr. e Hymenaea correana Barb. Rodr.), pertence à família Fabaceae (Leguminosae) e é conhecida por diferentes nomes populares: jatobá-capão, jatobá-da-casca-fina; jatobá-açu; jatobeiro; jatobá-do-campo; jataí-de-piauí, jatobá-de-vaqueiro e jatobá-do-cerrado (CARVALHO, 2007).

Os indivíduos dessa espécie ocorrem em áreas de cerrado e cerradão, apresentando altura que varia entre 6 e $9 \mathrm{~m}$, sendo sua madeira pesada, muito dura, resistente e moderadamente durável quando exposta. A espécie tem uso na construção naval e civil e também é indicada para a arborização urbana e nos plantios de áreas degradadas destinadas à recomposição da vegetação arbórea, sendo classificada como secundária tardia ou clímax (DURIGAN; NOGUEIRA, 1990; LORENZI, 2002). Os frutos de H. stigonocarpa são comestíveis e muito apreciados pelas populações rurais, que ingerem a polpa farinácea na forma in natura e como mingau, são também muito procurados por várias espécies da fauna (LORENZI, 2002; CARVALHO, 2007).

A espécie está incluída na categoria de "quase ameaçada de extinção", de acordo com Mori et al. (2012) e Barbosa et al. (2015). Uma espécie passa a ser considerada nessa categoria quando, ao ser avaliada por critérios quantitativos, não se qualifica atualmente como "criticamente em perigo", "em perigo" ou "vulnerável”, mas está perto dessas qualificações ou é provável que venha a se enquadrar em uma categoria de ameaça num futuro próximo (ICMBio, 2013).

A dormência física está presente nas sementes de H. stigonocarpa e é característica de muitas espécies tropicais (MORI et al., 2012; PIÑA-RODRIGUES;
MARTINS, 2012). Esse tipo de dormência causa uma redução total ou parcial à difusão de água ao embrião, em razão da impermeabilidade dos tecidos da semente e/ou do fruto (CARDOSO, 2004).

A dormência pode também representar um transtorno para os que exploram os viveiros de mudas, desejosos que estão de possuir grandes quantidades de sementes que germinem prontamente com vistas à produção de lotes uniformes de plantas (OLIVEIRA, 2007). Assim, desenvolveram-se artifícios para acelerar a germinação; são as chamadas técnicas de superação da dormência. Tais técnicas foram desenvolvidas após a observação das espécies na natureza, e continuam sendo aprimoradas à medida que as informações são difundidas. Como exemplos dessas técnicas podem se citadas: escarificação química; escarificação mecânica; imersão em água quente ou choque térmico; imersão em água fria; imersão em água corrente; estratificação a frio; alternância de temperatura e a combinação dessas técnicas, quando a semente de alguma espécie florestal exigir (BRASIL, 2009; PIÑA-RODRIGUES; MARTINS, 2012).

Outra área, em que a superação da dormência é importante, é na análise de sementes, pois, segundo Wielewicki et al. (2006), para se proceder à avaliação da qualidade de sementes de determinado lote, em laboratório, é necessário dispor de um padrão de germinação de sementes para cada espécie, já que cada uma delas apresenta suas particularidades quanto ao comportamento fisiológico e, portanto, germinativo. Um dos itens fundamentais para a padronização da germinação é a indicação de tratamentos prégerminativos para a superação da dormência de sementes de algumas espécies florestais (OLIVEIRA et al., 1996).

Cabe lembrar que o tratamento pré-germinativo utilizado deve ser efetivo na superação da dormência, 
sem prejudicar as sementes não dormentes, pois, dentro de um mesmo lote, pode haver sementes permeáveis e impermeáveis à água (EIRA et al., 1993).

Além disso, há poucos trabalhos (DE-CARVALHO et al., 2005; SOUZA et al., 2014) sobre a superação da dormência em sementes de H. stigonocarpa. De-Carvalho et al. (2005) testaram tratamentos de escarificação mecânica, com e sem embebição em água, com melhor resultado para escarificação mecânica com embebição das sementes. No estudo de Souza et al. (2014), os autores obtiveram resultados significativos para a escarificação mecânica, mas não para a química, em que utilizaram um tempo de embebição das sementes de três minutos em ácido sulfúrico. Com base na metodologia dos trabalhos analisados, não haviam sido estudados ainda um tempo maior de embebição das sementes em ácido sulfúrico nem o uso de outras substâncias como éter, acetona e ácido clorídrico, além do fogo. Essas outras substâncias e o fogo têm sido indicados como eficientes por outros autores para sementes florestais com dormência física (BIANCHETTI, 1981; MELO et al., 2004; SCREMIN-DIAS et al., 2006; ANDREANI JUNIOR et al., 2011; OLIVEIRA, 2012; GOMES et al., 2013).

Acrescente-se ainda que uma variação das respostas germinativas pode ocorrer entre espécies de um mesmo gênero (SUZUKI et al., 2010), sendo assim, a utilização de tratamentos pré-germinativos indicados para uma espécie, mas utilizados por outra do mesmo gênero, pode se mostrar contraproducente. Para H. courbaril, por exemplo, há um grande número pesquisas sobre esse tema (CARPANEZZI; MARQUES, 1981; ALMEIDA et al., 1999; GOMES et al., 2013; SAMPAIO et al, 2015; SOUZA; SEGATO, 2016).

Desse modo, este trabalho teve por objetivo avaliar diferentes tratamentos pré-germinativos em sementes de H. stigonocarpa e indicar quais podem ser aplicados para a promoção da germinação na espécie.

\section{Material e Métodos}

As sementes utilizadas neste estudo foram obtidas de um lote, coletado em Assis - SP, em 23/11/2009, armazenado em câmara seca com temperatura de $22^{\circ} \mathrm{C}$ e umidade relativa do ar em torno de $45 \%$.

Para a superação da dormência de sementes de $H$. stigonocarpa foram testados oito tratamentos: imersão em fogo, ácido sulfúrico, ácido clorídrico, acetona, éter e água fervente, além de escarificação mecânica com lixa seguida de corte do tegumento com alicate de unha, lavagem em água corrente por $2 \mathrm{~h}$ e testemunha.

A testemunha foi instalada sem nenhum tipo de tratamento. No tratamento com ácido sulfúrico, as sementes foram imersas no ácido durante 25 minutos, tomando por base resultados de outros trabalhos com espécies do mesmo gênero (MELO et al., 2004; GOMES et al., 2013), e depois lavadas em água corrente, durante 15 minutos, com o auxílio de uma peneira. A mesma técnica foi utilizada para os tratamentos com ácido clorídrico, acetona e éter, porém no ácido clorídrico as sementes permaneceram imersas por 30 minutos e, no éter e na acetona, por 20 minutos. Para o tratamento com fogo, as sementes foram imersas no álcool, durante 10 segundos, retiradas com auxílio de uma pinça e colocadas em contato com fogo, durante 5 segundos, e depois depositadas em um recipiente com água em temperatura ambiente, durante 60 segundos. $\mathrm{O}$ corte com alicate de unha e a escarificação mecânica com lixa foram realizados no tegumento até propiciar pequenas aberturas ou ranhuras, respectivamente, atingindo parte do cotilédone, em posição oposta à eclosão da radícula. No tratamento de água corrente, as sementes foram deixadas sob queda d'água pelo período de $2 \mathrm{~h}$, e no tratamento de água fervente (em ebulição), as sementes foram imersas em água a $100^{\circ} \mathrm{C}$ até que esta atingisse a temperatura ambiente.

Todas as sementes, após passarem pelos tratamentos ou não (testemunha), foram lavadas em hipoclorito de sódio a $2 \%$ durante 10 minutos e enxaguadas três vezes com água destilada. Cada tratamento teve cinco repetições de 20 sementes. Cada repetição foi montada em uma caixa acrílica transparente do tipo gerbox $(11$ x 11 x 3,5 $\mathrm{cm}$ ) e foi utilizado $30 \mathrm{~g}$ de vermiculita (esterilizada em estufa a $105^{\circ} \mathrm{C} / 24 \mathrm{~h}$ ) por repetição, sendo que as sementes foram instaladas entre esse substrato. $\mathrm{O}$ substrato de cada repetição recebeu $60 \mathrm{~mL}$ de água destilada (volume definido a partir de pré-testes) e em seguida foi feita a 
semeadura. As caixas foram colocadas no germinador a $30^{\circ} \mathrm{C}$, com fotoperíodo de $8 \mathrm{~h}$.

Os parâmetros analisados foram: germinação, sementes duras e firmes e sementes mortas com valores em porcentagem, além do Índice de Velocidade de Germinação (IVG), adotando a fórmula proposta por Maguire (1962). As sementes foram consideradas germinadas quando houve a emergência da radícula, em torno de $0,5 \mathrm{~cm}$ de comprimento, adotando o critério botânico de germinação (LABORIAU, 1983).

O delineamento experimental utilizado foi o inteiramente casualizado. Os dados expressos em porcentagem, referentes à germinação, foram transformados em arco seno $(\sqrt{ } \% / 100)$. Os tratamentos foram comparados pelo Teste de Duncan a $5 \%$ de probabilidade. O programa utilizado para realizar a análise estatística foi o ESTAT, da Universidade Estadual Paulista (UNESP), Campus de Jaboticabal/SP.

\section{Resultados e Discussão}

Os resultados de germinação, obtidos para as sementes de $H$. stigonocarpa, indicam que todos os tratamentos foram equivalentes e dois deles superiores (água a $100^{\circ} \mathrm{C}$ e ácido sulfúrico por 25 minutos) aos da testemunha (Figura 1). A testemunha apresentou $83 \%$ de germinação para as sementes e os tratamentos água a $100^{\circ} \mathrm{C}$ e imersão em ácido sulfúrico por 25 minutos apresentaram, respectivamente, $96 \%$ e $98 \%$. O Coeficiente de Variação para os dados de germinação foi de $11,70 \%$.

O uso do ácido sulfúrico, como tratamento prégerminativo (Figura 1), foi eficiente também com sementes de espécies do mesmo gênero, $H$. coubaril e H. parviflora, como demonstra o estudo de Carpanezzi e Marques (1981). Os autores indicaram para as duas espécies o tempo de imersão de 35 minutos no ácido sulfúrico, seguido da embebição em água por 12 h. Em

FIGURA 1: Valores médios da porcentagem de germinação de sementes de Hymenaea stigonocarpa submetidas a diferentes tratamentos pré-germinativos.

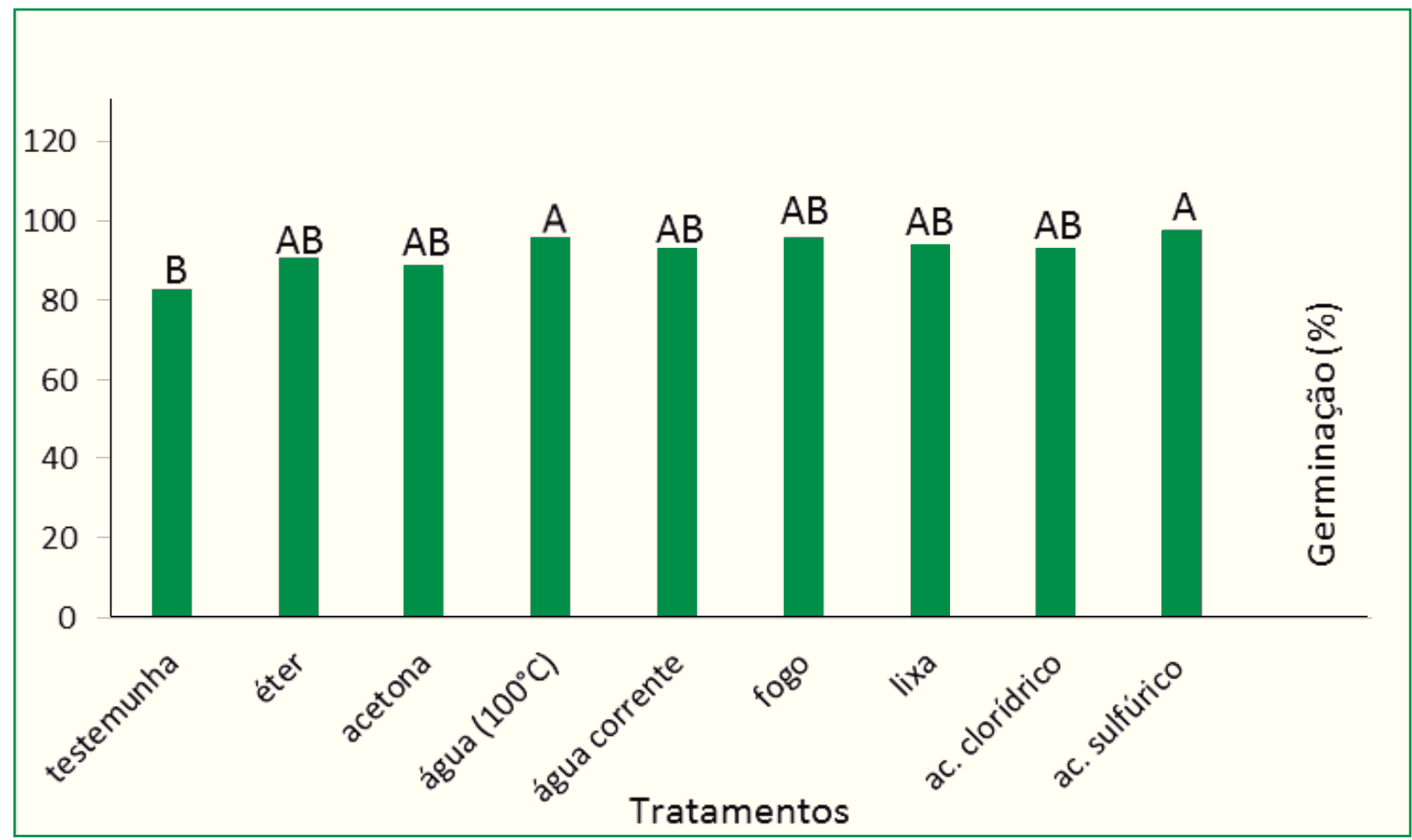


contrapartida, Souza et al. (2014) verificaram que a embebição das sementes de $H$. stigonocarpa em ácido sulfúrico por três minutos não foi eficiente na superação da dormência. Provavelmente o tempo de embebição das sementes em ácido sulfúrico, neste último estudo, não foi adequado para se conseguir escarificar o tegumento a ponto de proporcionar uma maior absorção de água e melhorar o desempenho germinativo.

O uso de água quente apresentou resultados conflitantes com os de Souza et al. (2014), com a mesma espécie (H. stigonocarpa), pois em um dos tratamentos testados as sementes foram embebidas em água a $80^{\circ} \mathrm{C}$ durante três minutos e apresentaram ao final do ensaio uma germinação menor que $40 \%$; outro tratamento, com a mesma temperatura e tempo de embebição, mas deixando as sementes posteriormente embebidas em água (em temperatura ambiente) por $24 \mathrm{~h}$ antes de serem semeadas, apresentou resultados semelhantes de germinação $(70 \%)$ aos do melhor tratamento, escarificação mecânica em dois lados da semente, testado pelos autores, e que obteve a germinação de $82 \%$.
O uso de mecanismos de superação da dormência acelera o processo de germinação e aumenta a porcentagem germinativa, assim como a uniformidade e a sobrevivência das plântulas. $\mathrm{O}$ fator limitante para a aplicação e eficiência desses tratamentos consiste na variabilidade do grau de dormência entre as sementes. O grau de dormência pode variar entre espécies, entre indivíduos e entre sementes do mesmo fruto (CARVALHO; NAKAGAWA, 2000; SILVA et al., 2010).

Com relação aos resultados obtidos para velocidade de germinação (Figura 2), cujo Coeficiente de Variação foi de $10,59 \%$, os tratamentos: água a $100^{\circ} \mathrm{C}$, ácido sulfúrico, fogo e lixa apresentaram valores estatisticamente superiores em relação aos outros tratamentos e a testemunha. Desses quatro melhores tratamentos (Figura 2), dois deles (água a $100^{\circ} \mathrm{C}$ e ácido sulfúrico) também apresentaram uma diferenciação, com relação à germinação, quando comparados à testemunha (Figura 1).

FIGURA 2: Valores médios de Índice de Velocidade de Germinação de sementes de Hymenaea stigonocarpa submetidas a diferentes tratamentos pré-germinativos.

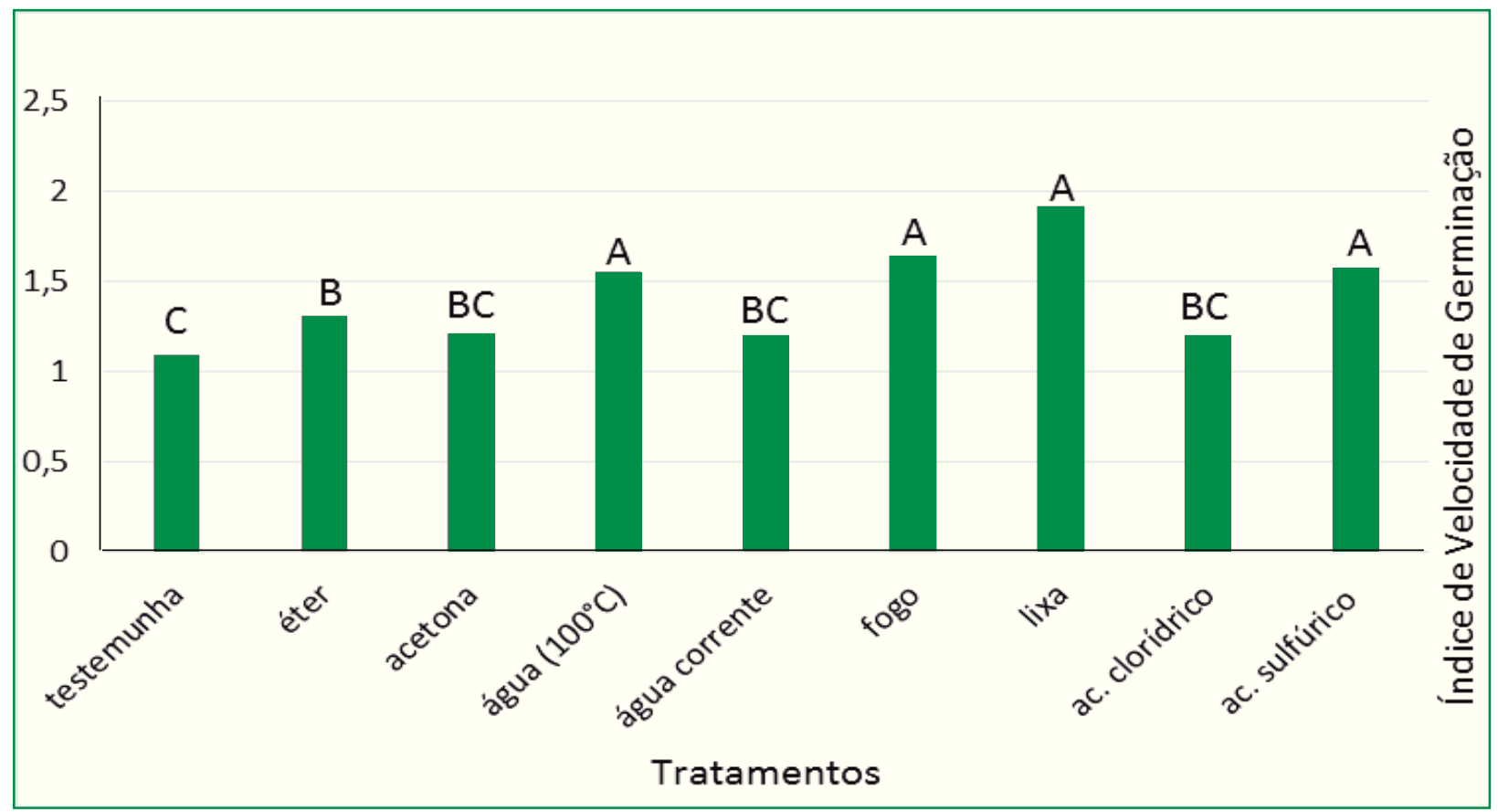


O efeito da superação de dormência na emergência de plântulas em casa de vegetação ou em campo pode variar entre espécies, como observado por Pereira et al. (2013), que conduziram um estudo com seis espécies florestais nativas, entre elas o jatobá do cerrado $(H$. stigonocarpa), e obtiveram como resultado para essa espécie, em casa de vegetação, que a superação da dormência de suas sementes, por meio de escarificação mecânica, proporcionasse um aumento do percentual de emergência de plântulas. Os mesmos autores ainda observaram que a superação de dormência aumentou o recrutamento de plantas de $H$. stigonocarpa.

Os resultados de sementes duras/firmes e mortas de H. stigonocarpa (Figura 3), cujos Coeficientes de Variação foram respectivamente $202,33 \%$ e $110,14 \%$, indicam que o uso da acetona proporcionou um alto percentual de sementes duras/firmes equivalente estatisticamente ao da testemunha. Essa substância também foi responsável por uma germinação nula em sementes de uma espécie florestal da mesma família, a Enterolobium contortisiliquum, cujas sementes foram imersas na acetona por curtos períodos (5 e 15 minutos) de acordo com Cruz-Silva e Rosa (2011).

Quando considerado o número de sementes mortas, observa-se que não houve diferenças estatísticas entre os tratamentos testados e a testemunha.

Desse modo, mesmo que vários tratamentos prégerminativos tenham bons resultados de germinação, é importante também que agilizem esse processo, pois assim as mudas produzidas tanto em viveiro como na semeadura direta apresentariam algumas vantagens como: tempo de produção e custo menores, diminuição do tempo de exposição ao ataque de pragas e doenças e a condições climáticas desfavoráveis.

Em áreas com estações seca e chuvosa bem definidas, como é o caso do bioma cerrado (onde ocorre H. stigonocarpa), é importante a superação da dormência das sementes, pois há um maior controle do tempo de emergência e, deste modo, diminuem-se as taxas de mortalidade por dessecação e aumenta-se o tempo que as plântulas emergidas têm durante a estação de

FIGURA 3: Valores médios percentuais de sementes duras/firmes e mortas de Hymenaea stigonocarpa submetidas a diferentes tratamentos pré-germinativos.

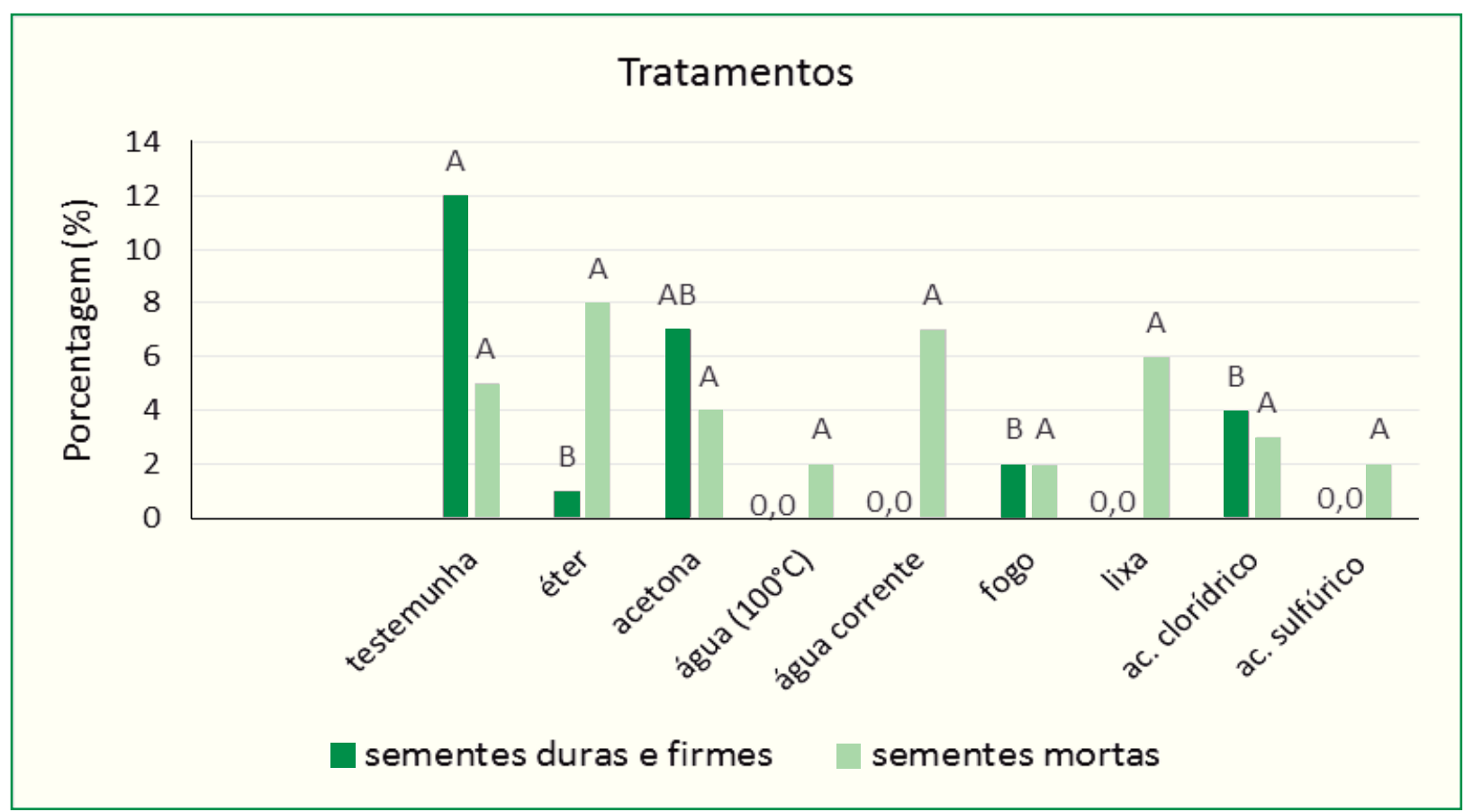


crescimento, antes do início de uma nova estação seca (SCHMIDT, 2008; PEREIRA et al., 2013).

Cabe observar que a variação dos resultados entre estudos de tratamentos pré-germinativos, para uma mesma espécie, pode ser devida às variações genéticoambientais entre as diferentes populações utilizadas (EIRA et al., 1993).

Os tratamentos testados neste estudo apresentam vantagens e desvantagens e, na análise destes, deve-se considerar, além dos seus resultados experimentais, também a praticidade e o custo efetivo de cada um deles na tomada de decisão sobre qual ou quais utilizar.

Sendo assim, as considerações que se seguem têm o objetivo de contribuir na escolha do tratamento mais indicado para uso com sementes desta espécie. A água fervente $\left(100^{\circ} \mathrm{C}\right)$ é um tratamento que apresenta baixo custo e facilidade de uso como maiores vantagens, embora o técnico deva ter cuidado ao manipulá-la (principalmente nos primeiros minutos, quando a temperatura ainda é alta); já o ácido sulfúrico é uma substância que, para ser obtida, precisa de autorização de compra (BRASIL, 2003) e um maior cuidado ao manipulá-la. Com relação ao fogo, é uma técnica ainda pouco empregada com espécies nativas, pois, de acordo com Andreani Junior et al. (2011), raros estudos utilizam esse tipo de tratamento, embora o fogo seja citado como um dos fatores ambientais envolvidos na quebra da dormência de sementes (BRYANT, 1989); a sua metodologia ainda deve ser mais pesquisada, pois tem potencial de uso. Por fim, a escarificação mecânica, que pode, por exemplo, ser utilizada em tambores rotativos forrados internamente com lixa (FOWLER; BIANCHETTI, 2000) para se ter uma maior quantidade de sementes escarificadas, mas é necessário um ajuste no equipamento para não danificar o cotilédone ou o eixo embrionário.

Ao término deste estudo, deve ser considerada a ampliação das pesquisas com: a) tempo de imersão das sementes de H. stigonocarpa para as substancias testadas, b) temperatura da água quente, c) locais de escarificação no tegumento da semente e d) tempo da semente sob uma chama, para que se avalie a necessidade de alterações no uso da metodologia proposta.
Em síntese, quando se consideram os resultados dos parâmetros analisados (germinação, Índice de Velocidade de Germinação, sementes duras/firmes e sementes mortas), podem ser indicados para a superação da dormência em sementes de H. stigonocarpa os seguintes tratamentos: a) germinação - todos os tratamentos testados se equivalem estatisticamente, embora somente dois, a imersão em água a $100^{\circ} \mathrm{C}$ e o ácido sulfúrico, tenham apresentado germinação superior aos da testemunha, b) Índice de Velocidade de Germinação - quatro tratamentos: a imersão em água a $100^{\circ} \mathrm{C}$, o fogo, a lixa e o ácido sulfúrico tiveram resultados superiores e diferenciam-se estatisticamente dos valores da testemunha, c) sementes duras/firmes - excetuando a acetona, todos os outros tratamentos apresentam resultados inferiores aos resultados da testemunha e d) sementes mortas - todos os tratamentos se equivalem estatisticamente à testemunha.

Sendo assim, quando se consideram os resultados de germinação, Índice de Velocidade de Germinação, sementes duras e firmes e sementes mortas, dois tratamentos se sobressaem, embora não se diferenciem de outros, em cada um dos parâmetros analisados. São os tratamentos: água a $100^{\circ} \mathrm{C}$ e o ácido sulfúrico. O seu uso é interessante, pois estão sempre entre os melhores tratamentos em relação aos parâmetros analisados.

\section{Referências}

ALMEIDA, M. J. B.; FERRAZ, I. D. K.; BASSINI, F. Estudos sobre a permeabilidade do tegumento e a germinação de sementes de Hymenaea courbaril L. (Caesalpinioideae), uma espécie de uso múltiplo. Revista da Universidade do Amazonas: Série Ciências Agrárias, Manaus, v. 8, n. 1-2, p. 63-71, 1999.

ANDREANI JUNIOR, R.; CARDOSO, R. D.; SANTOS, N. S. S.; SANTOS, S. R. G.; KOZUSNY-ANDREANI, D. I. Superação da dormência de sementes de três essências florestais. Revista do Instituto Florestal, São Paulo, v. 23, n. 2, p. 255-264, 2011.

BARBOSA, L. M.; SHIRASUNA, R. T.; LIMA, F. C.; ORTIZ, P. R. T. Lista de espécies indicadas para restauração ecológica para diversas regiões do estado de São Paulo. In: SIMPÓSIO DE RESTAURAÇÃo ECOLÓGICA, VI, 2015, São Paulo. Anais... São Paulo: Instituto de Botânica, 2015. p. 303-436.

BRASIL. Presidência da República - Sub-chefia de Assuntos Jurídicos. Portaria n⿳⺈ 1.274, de 25 de agosto de 2003. Estabelece normas de controle e fiscalização sobre produtos químicos que direta ou indiretamente possam ser destinados à elaboração ilícita de substâncias entorpecentes, psicotrópicas ou que determinem dependência física ou psíquica, e dá outras providências (ANEXO 12). 
BRASIL. Ministério da Agricultura Pecuária e Abastecimento. Regras para análise de sementes. Secretaria de Defesa Agropecuária. Brasília: Mapa/ACS, 2009. 399 p.

BIANCHETTI, A. Tecnologia de sementes de essências florestais. Revista Brasileira de Sementes, Brasília, v. 3, n. 3, p. 27-46, 1981. BRYANT, J. A. Fisiologia da semente. São Paulo: EPU, 1989. 86 p. CARDOSO, V. J. M. Dormência: estabelecimento do processo. In: FERREIRA, A. G.; BORGHETTI, F. (Ed.). Germinação: do básico ao aplicado. Porto Alegre: Artmed, 2004. p. 95-108.

CARPANEZZI, A. A.; MARQUES, L. C. T. Germinação de sementes de jutaí-açu (Hymenaea courbaril L.) e de jutaímirim (H. parvifolia Huber) escarificadas com ácido sulfúrico comercial. Circular Técnica 19. Belém: EMBRAPA-CPATU, 1981. $15 \mathrm{p}$.

CARVALHO, N. M.; NAKAGAWA, J. Sementes: ciência, tecnologia e produção. 4. ed. Jaboticabal: FUNEP, 2000. 588 p.

CARVALHO, P. E. Jatobá-do-cerrado - Hymenaea stigonocarpa. Circular Técnica, no 133. Colombo: Embrapa Floresta, 2007. 8 p.

CRUZ-SILVA, C. T. A. C.; ROSA, A. P. M. Tratamentos para superação da dormência em sementes de orelha-de-negro (Enterolobium contortisiliquum (Vell.) Morong). Varia Scientia Agrárias, Cascavel, v. 2, n. 2, p. 79- 90, 2011.

DE-CARVALHO, P. S.; MIRANDA, S. C.; SANTOS, M. L. Germinação e dados biométricos de Hymenaea stigonocarpa Mart. Ex Hayne (Leguminosae-Caesalpinoideae) - Jatobá-doCerrado. Revista Anhanguera, Goiânia, v. 6, n. 1, p. 101-116, 2005. DURIGAN, G.; NOGUEIRA, J. C. B. Recomposição de matas ciliares. São Paulo: Instituto Florestal, 1990. 14 p. (IF Sér. Reg., 4) EIRA, M. T. S.; FREITAS, R. W. A.; MELLO, C. M. C. Superação da dormência de sementes de Enterolobium contorsiliquum (Vell.) Morong - Leguminosae. Revista Brasileira de Sementes, Brasília, v. 15, n. 2, p. 177-181, 1993.

FOWLER, J. A. P.; BIANCHETTI, A. Dormência em sementes florestais. Documento 40. Colombo: EMBRAPA-Florestas, 2000. $27 \mathrm{p}$.

GOMES, M. B.; FARIA, A. A.; CERQUEIRA, D. S.; BAILÃO, L. L. Avaliação de métodos para a superação de dormência de sementes de jatobá (Hymenaea courbaril L.). Revista Eletrônica Interdisciplinar, Barra do Garças, v. 2, n. 9, p. 6-9, 2013.

ICMBio. Aplicação de critérios e categorias da UICN na avaliação da fauna brasileira. Brasília: Instituto Chico Mendes de Conservação da Biodiversidade, 2013. 45 p.

LABOURIAU, L. G. A germinação da semente. Washington: Secretaria Geral da Organização dos Estados Americanos, 1983. $173 \mathrm{p}$.

LORENZI, H. Árvores brasileiras: manual de identificação e cultivos de plantas arbóreas do Brasil. Nova Odessa: Instituto Plantarum, v. 1, 2002. 368 p.

MAGUIRE, J. D. Speed of germination-aid in selection and evaluation for seedling emergence and vigor. Crop Science, Madison, v. 2, n. 1, p. 176-177, 1962.

MELO, M. G. G.; MENDONÇA, M. S.; MENDES, A. M. S. Análise morfológica de sementes, germinação e plântulas de jatobá (Hymenaea intermedia Ducke var. adenotricha (Ducke) Lee \& Lang.) (Leguminosae-caesalpinioideae). Acta Amazonica, Manaus, v. 34, n. 1, p. 9-14, 2004.
MORI, E. S.; PIÑA-RODRIGUES, F. C. M.; IVANAUSKAS, N. M.; FREITAS, N. P.; BRANCALION, P. H. S.; MARTINS, R. B. Guia para germinação de 100 espécies nativas. In: MORI, E. S.; PIÑA-RODRIGUES, F. C. M.; FREITAS, N. P. (Ed.). Sementes florestais: guia para germinação de 100 espécies nativas. São Paulo: Instituto Refloresta, 2012. p. 29-154.

OLIVEIRA, E. C.; PIÑA-RODRIGUES, F. C. M.; FIGLIOLIA, M. B. Propostas para a padronização de metodologias em análise de sementes florestais. Revista Brasileira de Sementes, Brasília, v. 11, n. 1/2/3, p. 1-42, 1996.

OLIVEIRA, O. S. Tecnologia de sementes florestais. Curitiba: Imprensa Universitária, 2007. 185 p.

OLIVEIRA, O. S. Tecnologia de sementes florestais: espécies nativas. Curitiba: Ed. da UFPR, 2012. 404 p.

PEREIRA, S. R.; LAURA, V. A.; SOUZA, A. L. T. Superação de dormência de sementes como estratégia para restauração florestal de pastagem tropical. Pesquisa Agropecuária Brasileira, Brasília, v. 48, n. 2, p. 148-156, 2013.

PIÑA-RODRIGUES F. C. M.; MARTINS, R. B. Dormência: conceito, tipos e formas de superação. In: MORI, E. S.; PIÑARODRIGUES, F. C. M.; FREITAS, N. P. (Ed.). Sementes florestais: guia para germinação de 100 espécies nativas. São Paulo: Instituto Refloresta, 2012. p. 19-26.

SAMPAIO, M. F.; COUTO, S. R.; SILVA, C. A.; SILVA, A. C. A.; DA SILVA, A. A. S.; TEIXEIRA, A. L. Influência de diferentes substratos associados a métodos de superação de dormência na germinação e emergência de sementes de jatobá (Hymenaea courbaril L.). Revista Farociência, Cuiabá, v. 2, n. 1, p. 11-27, 2015.

SCHMIDT, L. A review of direct sowing versus planting in tropical afforestation and land rehabilitation. Copenhagen: Forest and Landscape, 2008. 37p. (Development and Environment, $10)$.

SCREMIN-DIAS, E.; KALIFE，C.; MENEGUCCI, Z. R. H.; SOUZA, P. R. Produção de mudas de espécies florestais nativas: manual. Campo Grande: UFMS, 2006, 59 p.

SILVA, A. C.; CRUZ, E. D.; SOUZA, G. T.; ALBUQUERQUE, G. D. P. Germinação de sementes de matrizes de taxi-branco (Sclerolobium paniculatum Vogel.). In: SEMINÁRIO DE INICIAÇÃO CIENTÍFICA, 14, 2010. Anais... Belém: Embrapa Amazônia Oriental, 2010. 4 p.

SOUZA, T. R. B; SILVA, I. M. A.; SOUZA, A. M. Superação de dormência de sementes de Hymenaea stigonocarpa Mart. em laboratório. In: SIMPÓSIO BRASILEIRO DE PÓSGRADUAÇÃO EM CIÊNCIAS FLORESTAIS, 8, 2014, Recife. Anais... Recife: UFRPE, 2014. p. 32-36.

SOUZA, V. M. S.; SEGATO, S. V. Superação de dormência em sementes de jatobá (Hymenaea courbaril L.). Nucleus, Ituverava, v. 13, n. 1, p. 71-80, 2016.

SUZUKI, R.; ALMEIDA, V.; PESCADOR, R.; FERREIRA, W. Germinação e crescimento in vitro de Cattleya bicolor Lindley (Orchidaceae). Hoehnea, São Paulo, v. 37, n. 4, p. 731-742, 2010.

WIELEWICKI, A. P.; LEONHARDT, C.; SCHLINDWEIN, G.; MEDEIROS, A. C. S. Proposta de padrões de germinação e teor de água para sementes de algumas espécies florestais presentes na região sul do Brasil. Revista Brasileira de Sementes, Londrina, v. 28, n. 3, p. 191-197, 2006. 